\title{
HIDROGEOLOGIA DO DISTRITO FEDERAL: BASES PARA A GESTÃO DOS RECURSOS HÍDRICOS SUBTERRÂNEOS
}

\author{
JOSÉ ELOI GUIMARÃES CAMPOS
}

\begin{abstract}
In the Federal District of Brazil, the groundwater must be taken as a strategic resource once the aquifers are of low capacity of water reservation. Due to this scenario the groundwater may be applied in specific activities including water supply of little communities, industry areas or in service stations. The increase in usage of groundwater, associated to the inadequate occupation of land and watershed result in many problems related to the aquifer exploration. It is necessary to develop management practices to get the sustainability of the system. So that the management processes reach the expected results, the applied techniques must be integrated and related to the filter, regulatory and reservoir functions of the aquifers. Among the actions to be developed the most important are the construction of wells according to the technical norms, definition of the protection perimeters of wells and aquifer recharge areas, improvement in the investments on sanitation, restriction of surface sealing in areas of regional recharge conditions, application of artificial aquifer recharge project, mapping the vulnerability and the contamination risk of the aquifers, development of control systems of the demand outputs and increase the financial resources to scientific study of the groundwater system
\end{abstract}

Keywords: Groundwater management, fractured aquifers.

Resumo Em função dos tipos de aquúferos presentes no Distrito Federal e sua limitada capacidade de reservação e circulação, a água subterrânea deve ser utilizada como um recurso estratégico aplicado a setores específicos da economia ou como fonte de abastecimento de pequenos centros urbanos ou núcleos rurais. O contínuo incremento do uso das águas subterrâneas, aliado ao uso e ocupação inadequados do território resultou em uma série de problemas relativos ao aproveitamento dos aquíferos. Dessa forma, é cada vez mais necessário que práticas de gestão sejam desenvolvidas para que o sistema se torne sustentável. Para que o processo de gerenciamento alcance os resultados esperados é fundamental que as práticas sejam integradas e que sejam aplicadas às principais feições funcionais dos aquíferos, incluindo suas funções filtro, reguladora e reservatório. Dentre as práticas a serem desenvolvidas destacam-se a construção adequada dos pontos de captação, a definição de perímetros de proteção sanitária dos poços e áreas de recarga, investimentos em saneamento básico, limitação da impermeabilização de áreas de recarga regionais, aplicação de projetos de recarga artificial de aquíferos, cartografia da vulnerabilidade e risco de contaminação, desenvolvimento de controles com outorga e cobrança pelo uso e maior investimento no conhecimento dos sistemas aquíferos.

Palavras-chave: Água subterrânea, gestão, aquíferos fraturados.

INTRODUÇÃO O uso de água subterrânea no Distrito Federal apresentou um grande incremento nos últimos 15 anos em função do novo modelo de ocupação do solo adotado. A partir da segunda metade da década de 80 , com o advento e a expansão dos condomínios e a ampliação de núcleos urbanos consolidados, a água subterrânea passou a desempenhar um papel de maior importância no abastecimento público. Nesse período, estima-se que o número de poços tubulares profundos na região do Distrito Federal tenha triplicado, passando de cerca de 1.500 para 4.500 poços.

O aumento da demanda pela água subsuperficial está diretamente relacionado ao aumento da densidade populacional em regiōes fora do alcance do Sistema Integrado de Abastecimento da Companhia de Saneamento de Brasília (CAESB). Nesse contexto, a necessidade de gestão adequada desses recursos é vital para a manutenção dos sistemas aqüíferos e definição de sua autosustentabilidade.

Para o desenvolvimento de uma gestão ativa dos reservatórios subterrâneos é necessário o conhecimento dos aspectos técnicos referentes aos sistemas e subsistemas aqǘf́eros, incluindo os tipos, condições de recarga, vazões médias, reservas, parâmetros dimensionais entre outros. Além dos fatores do meio físico ainda é muito importante conhecer o perfil dos usuários e as demandas atuais e futuras.

A gestão ativa dos aqüíferos deve atuar diretamente nas suas várias funções e quando possível envolver a gestão integrada dos recursos hídricos superficiais e subterrâneos.

O objetivo do presente texto é apresentar propostas para a gestão das águas subterrâneas do Distrito Federal, enfatizar os maiores problemas relacionados a sua explotação e definir estratégias para minimizar os impactos aos reservatórios subterrâneos. Uma descrição sucinta dos aspectos do meio físico será apresentada para situar o leitor nos aspectos de geologia, hidrogeologia, geomorfologia, clima e solos da região.

CARACTERIZAÇÃODOMEIOFÍSICO Geologia Ageologia do Distrito Federal foi recentemente revista e atualizada a partir da confecção de um novo mapa geológico sem as coberturas de solos, desenvolvido por Freitas-Silva \& Campos (1998). O Distrito Federal, por estar localizado na porção central da Faixa de Dobramentos e Cavalgamentos Brasília (Marini et al. 1981) na sua transição das porções internas (de maior grau metamórfico) e externas 
(de menor grau metamórfico), apresenta uma estruturação geral bastante complexa com superimposição de dobramentos com eixos ortogonais.

Quatro conjuntos litológicos distintos compõem o contexto geológico regional do DF: os grupos Paranoá, Canastra, Araxá e Bambuí e suas respectivas coberturas de solos residuais ou coluvionares. Os grupos Paranoá e Canastra apresentam idade meso/neoproterozóica e os grupos Araxá e Bambuí, idade neoproterozóica (Fig. 1).

O Grupo Paranoá ocupa cerca de $65 \%$ da área total do Distrito Federal, sendo possível caracterizar sete unidades litoestratigráficas correlacionáveis, da base para o topo, com as seqüências deposicionais $\mathbf{Q}_{2} \mathbf{S}, \mathbf{A}, \mathbf{R}_{3}, \mathbf{Q}_{3}, \mathbf{R}_{4}$ e $\mathbf{P C}$ das áreas-tipo da região de Alto Paraíso de Goiás (Faria 1995). A Unidade $\mathbf{Q}_{2}$ é caracterizada por quartzitos médios com leitos conglomeráticos em direção ao topo do pacote. Ocorre ampla variedade de estratificações cruzadas, inclusive com tipo revirada, indicando retrabalhamento por meso e macro marés. Ocorre restritamente na borda leste do Domo Estrutural do Pipiripau.

A Unidade $\mathrm{S}$ no Distrito Federal é composta por metassiltitos maciços e metarritmitos arenosos próximos ao topo da seqüência, localmente podem ocorrer camadas de quartzitos estratificados e mais raramente são observadas, em poços, lentes de metacalcário micrítico cinza.

A Unidade das ardósias é constituída por um expressivo conjunto de ardósias roxas, homogêneas, dobradas, com forte clivagem ardosiana e com ocasionais lentes irregulares de quartzitos, que ocupam variadas posições estratigráficas. As ardósias são cinza escuro, quando frescas, e intensamente fraturadas em afloramentos. O acamamento sedimentar é a única estrutura sedimentar observada em afloramentos.

Os metarritmitos da Unidade $\mathbf{R}_{3}$ são caracterizados por intercalações irregulares de quartzitos finos, brancos e laminados com camadas de metassiltitos, metalamitos e metassiltitos argilosos com cores cinza escuro, quando frescos, que passam para tons rosados a avermelhados, quando próximos à superfície. Além do acamamento, podem ser observadas estratificações do tipo sigmoidais e hummockys e marcas onduladas.

A Unidade $\mathbf{Q}_{3}$ é composta por quartzitos finos a médios, brancos ou rosados, silicificados e intensamente fraturados. Apresentam estratificações cruzadas variadas e mais raramente marcas onduladas. Sustenta o relevo de chapadas elevadas em cotas superiores a $1.200 \mathrm{~m}$.

Sobrepondo a Unidade $\mathbf{Q}_{3}$ ocorrem os metarritmitos argilosos

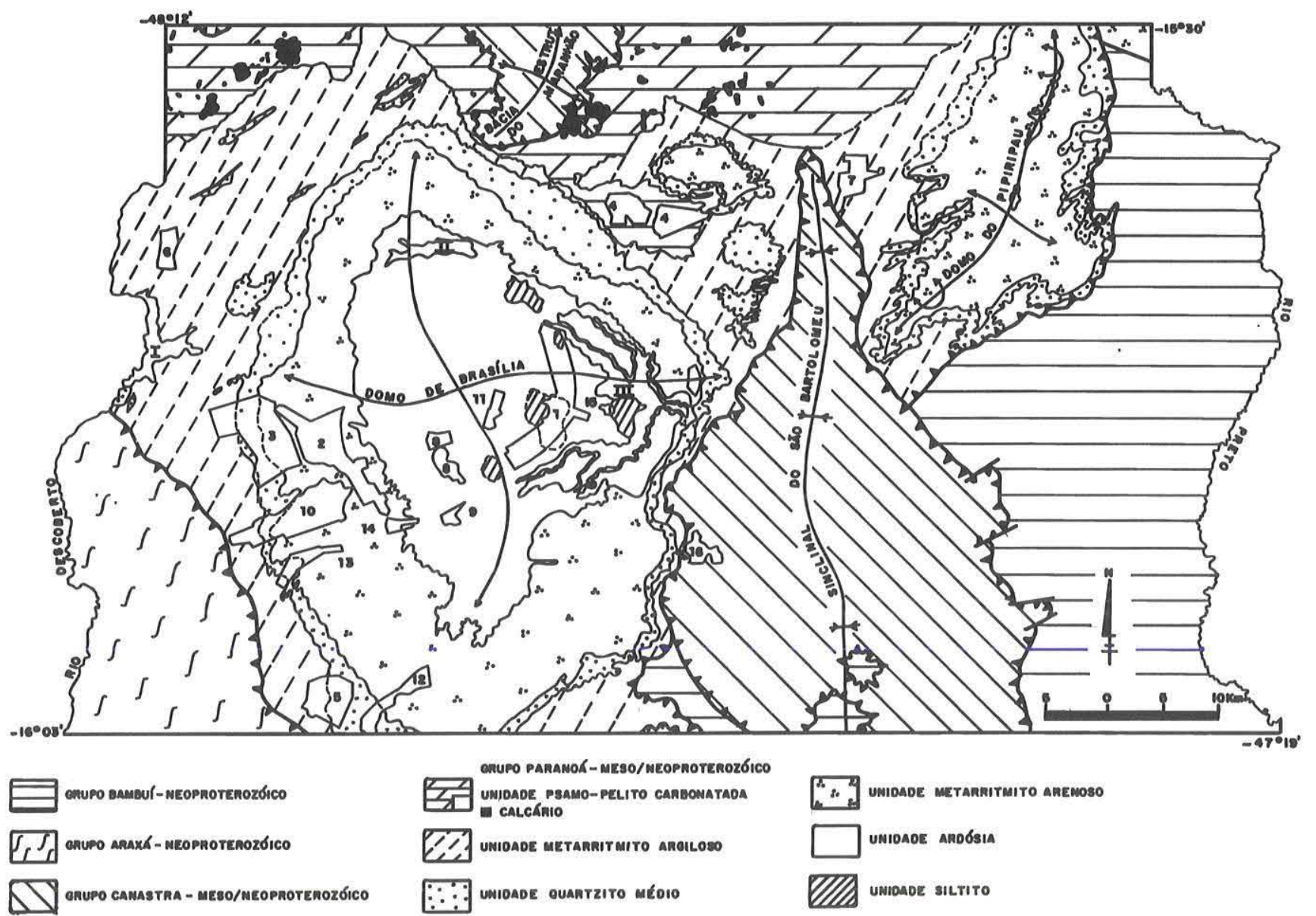

Figura 1 - Mapa geológico simplificado do Distrito Federal. Os números representam os centros urbanos consolidados: 1 Brasília, 2 - Taguatinga, 3 - Ceilândia, 4 - Sobradinho, 5 - Gama, 6 - Brazlândia, 7 - Planaltina, 8 -Cruzeiro, 9 - Núcleo Bandeirante, 10 - Samambaia, 11 - Setor Sudoeste, 12 - Santa Maria, 13 - Recanto das Emas, 14 - Riacho Fundo, 15 - Vila Planalto e 16 - São Sebastião. 
da Unidade $\mathbf{R}_{4}$. Esses são constituídos por intercalações regulares de quartzitos e metapelitos, com espessuras bastante regulares da ordem de 1 a $3 \mathrm{~cm}$. Apenas raramente são discriminados pacotes decimétricos de metassiltitos maciços.

Como última unidade litoestratigráfica, destaca-se a Unidade Psamo Pelito Carbonatada composta por lentes de metacalcários, camadas e lentes de quartzitos pretos e grossos interdigitados com metassiltitos e metargilitos com cores amareladas, que passam a tons rosados quando alterados.

O Grupo Canastra ocupa cerca de $15 \%$ da área total do DF, sendo distribuído pelos vales dos rios São Bartolomeu (na porção central do DF) e Maranhão (na porção centro-norte do DF). É constituído essencialmente por filitos variados, os quais incluem clorita filitos, quartzo-fengita filitos e clorita-carbonato filitos. Além dos filitos ocorrem subordinadamente, na forma de lentes decamétricas, mármores finos cinza-claro e quartzitos finos silicificados e cataclasados. No DF ocorrem metassedimentos correlacionáveis às formações Serra do Landim e Paracatu (FreitasSilva \& Dardenne 1994)

O Grupo Araxá está limitado ao setor sudoeste do Distrito Federal, ocupando apenas 5\% da área total do território. É composto por xistos variados com ampla predominância de muscovita xistos e ocorrências restritas de clorita xistos, quartzo-muscovita xistos, granada xistos e lentes de quartzitos micáceos.

Por fim, o Grupo Bambuí se distribui por cerca de $15 \%$ da área total do DF, sendo observado na porção leste ao longo do Vale do Rio Preto. É composto por metassiltitos laminados, metassiltitos argilosos e bancos de arcóseos, com cor de alteração rosada/ avermelhada e com cor de rocha fresca em vários tons de verde.

A evolução estrutural é caracterizada por cinco fases de deformação dentro de um único evento compressivo, relacionado à Orogênese Brasiliana. As várias fases foram estruturadas em função de estágios compressivos (Fases $\mathrm{F}_{1}$ a $\mathrm{F}_{4}$ ) seguidos por um estágio final extensivo (Fase $\mathrm{F}_{5}$ ). Toda a deformação foi controlada por três sistemas de cavalgamentos denominados de Sistema de Cavalgamento Paranã (responsável pelo posicionamento do Grupo Paranoá sobre o Grupo Bambuí); Sistema de Cavalgamento São Bartolomeu/Maranhão (que coloca o Grupo Canastra sobre os grupos Paranoá e Bambuí) e Sistema de Cavalgamento Descoberto (o qual sobrepõe o Grupo Araxá ao Grupo Paranoá). Para maiores detalhes do ponto de vista estrutural ver Freitas-Silva \& Campos (1998).

Geomorfologia O Distrito Federal está localizado no Planalto Central do Brasil, onde se localizam as cabeceiras de afluentes dos três maiores rios brasileiros - o Rio Maranhão (afluente do Rio Tocantins), o Rio Preto (afluente do Rio São Francisco) e os rios São Bartolomeu e Descoberto (tributários do Rio Paraná).

Os estudos de geomorfologia da região do Distrito Federal contam com um importante acervo de trabalhos, entre os quais merecem destaque Maio (1986), Novaes Pinto(1986ab, 1987, e 1994ab), Novaes Pinto \& Carneiro (1984) e Martins \& Baptista (1998).

A compartimentação geomorfológica do território do DF inclui as Regiões de Chapadas, Regiões de Dissecação Intermediária, Regiões Dissecadas de Vales, Regiões de Rebordo e Regiões de Escarpas.

Dentre os fatores responsáveis pela evolução morfodinâmica do Distrito Federal, destacam-se o clima, o tipo de vegetação, a evolução dos perfis de alteração, a estruturação neotectônica além de processos de incisão de vales nas amplas chapadas elevadas. O substrato litológico apresenta um notável controle da compartimentação e evolução geomorfológica. Todas as Chapadas elevadas são controladas pela presença de tipos petrográficos atribuídos às unidades $\mathbf{R}_{3}$ e $\mathbf{Q}_{3}$ do Grupo Paranoá. As Regiões de Dissecação Intermediárias são controladas por rochas pelíticas (e.x. Unidade das Ardósias e Grupo Bambuí). Os Vales Dissecados são condicionados por unidades muito impermeáveis, com pequena capacidade de infiltração e maior potencial erosivo, condicionados por rochas dos grupos Canastra, Araxá e Unidade Psamo Pelito Carbonatada do Grupo Paranoá. Os rebordos e escarpas são controlados pela região de transição ou contato brusco entre litologias com alto contraste de erodibilidade.

Portanto a geologia é o principal condicionante das variações de altitude, incisão de vales, densidade, forma da rede de drenagem e, principalmente, da evolução morfodinâmica e da paisagem atual do Distrito Federal.

Climatologia O clima do Distrito Federal é marcado pela forte sazonalidade, com dois períodos distintos bem caracterizados. O período entre maio e setembro é evidenciado pela baixa taxa de precipitação, baixa nebulosidade, alta taxa de evaporação, com muito baixas umidades relativas diárias (tendo sido registrados valores inferiores a $15 \%$ ). O período entre outubro e abril apresenta padrões contrastantes, sendo que os meses de dezembro a março concentram $47 \%$ da precipitação anual.

Segundo a classificação climática de Köppen (in CODEPLAN 1984), no Distrito Federal podem ocorrer, em função de variações de temperaturas médias (dos meses mais frios e mais quentes) e de altitude, climas do tipo: Tropical Aw, Tropical de Altitude Cwa e Tropical de Altitude Cwb.

A precipitação média anual é da ordem de $1500 \mathrm{~mm}$, sendo que existe uma distribuição irregular, onde as menores alturas pluviométricas anuais ocorrem na porção leste e as taxas mais elevadas estão concentradas em dois pontos a NE e SE do Distrito Federal (Baptista 1998).

Estimativas de Coimbra (1987) mostram que cerca de $12 \%$ da precipitação total infiltram na zona vadosa efetivamente alcançando a zona saturada do aqüífero. A evapotranspiração real fica em torno de $900 \mathrm{~mm}$ anuais, sendo que os meses de maio a setembro apresentam déficit hídrico, enquanto o período de outubro a abril apresenta superávit.

Um efeito anômalo da distribuição das precipitações é observado durante os veranicos de janeiro. Esse fator climático é conhecido pelos agricultores da região do cerrado e em muitos anos é responsável pela quebra da produção agrícola da Bacia do Rio Preto, onde o efeito é mais acentuado.

DEFINIÇÃOECLASSIFICAÇÃODOSAQÜÍFEROS ODistrito Federal está situado, no contexto brasileiro, na denominada Província Hidrogeológica do Escudo Central,a qual inclui parcialmente a Faixa de Dobramentos Brasília e se estende para norte/ noroeste, ocupando a Faixa de dobramentos Paraguai/Araguaia e a parte sul do Cráton Amazônico. Esta província é amplamente dominada por aquíferos fraturados cobertos por mantos de intemperismo (solos e rochas alteradas) com características físicas e espessuras variáveis.

O polígono do Distrito Federal está situado em um alto regional que não apresenta grandes drenagens superficiais, sendo um divisor natural de três grandes bacias hidrográficas. Por isso, as águas subterrâneas têm função estratégica na manutenção de vazões dos cursos superficiais e no abastecimento de núcleos rurais, urbanos e condomínios situados fora do Sistema Integrado 
de Abastecimento da Companhia de Saneamento de Brasília CAESB ou ainda em áreas onde não existem sistemas alternativos de captação de pequenas drenagens.

As principais informações sobre a hidrogeologia do Distrito Federal estão disponíveis em Romano \& Rosas (1970), Barros (1987e 1994), Amore (1994), Mendonça (1993), Campos \& FreitasSilva (1998 e 1999), Zoby (1999), Souza (2001), Cadamuro (2002)e Joko (2002).

No Distrito Federal, onde a geologia é caracterizada por rochas metamórficas, recobertas por espessos solos, podem ser diferenciados dois grandes grupos de aqüíferos, que correspondem à classificação maior dos reservatórios subterrâneos de água, o Domínio Aqüífero Poroso e o Domínio Aquífero Fraturado (que também inclui porções cársticas restritas). No caso do Distrito Federal, onde há grande variação de tipos litológicos dentro das várias unidades litoestratigráficas, a melhor caracterização dos vários sistemas requer a subdivisão em subsistemas, evidenciando a real diversificação dos domínios, sistema e subsistemas aquíferos. A Tabela 1 mostra a sinopse do quadro hidrogeológico do Distrito Federal.

Domínio Poroso Os aquíferos do Domínio Poroso são caracterizados pelos meios geológicos onde os espaços vazios totais (porosidade) são intergranulares, ou seja, a água ocupa os poros entre os minerais constituintes do corpo rochoso. Como no Distrito Federal não existem rochas sedimentares com espaços intersticiais, esse domínio é representado pelos solos, pelo manto de alteração das rochas (saprolito) e por materiais acumulados em calhas de drenagens (aluviões). A importância local dos aqüíferos desse domínio está vinculada a vários parâmetros, dos quais dois são destacados: a espessura saturada (b) e a condutividade hidráulica $(\mathrm{K})$, sendo que ambas são diretamente controladas pela geologia e pela geomorfologia de seu substrato.

No Distrito Federal os aquíferos porosos são compostos por meios geológicos não consolidados, com espessuras variando de poucos centímetros até $80 \mathrm{~m}$, com ampla predominância $(>60 \%)$ de espessuras entre 15 e $25 \mathrm{~m}$, grande extensão e continuidade lateral $\mathrm{e}$, de forma geral, homogêneos. Os aquíferos relacionados a esse domínio são classificados como aquíf́eros livres e/ou suspensos,

Tabela I - Resumo da classificação dos Dominios, Sistemas/ Subsistemas aqüíferos do Distrito Federal com respectivas vazões médias. Fonte: Campos \& Freitas-Silva (1999).

\begin{tabular}{|c|c|}
\hline $\begin{array}{l}\text { AQÜIFERO } \\
\text { (Sistema/Subsistema) }\end{array}$ & MÉDIAS DAS VAZÕES $(\mathrm{I} / \mathrm{h})$ \\
\hline \multicolumn{2}{|c|}{ AQÜÍFEROS DO DOMÍNIO POROSO } \\
\hline SISTEMAS $\mathbf{P}_{1}, \mathbf{P}_{2}, \mathbf{P}_{3}$ e $\mathbf{P}_{4}$ & $<800$ \\
\hline \multicolumn{2}{|c|}{ AQÜÍFEROS DO DOMIINIO FRATURADO } \\
\hline \multicolumn{2}{|c|}{ SISTEMA PARANOÁ } \\
\hline Subsistema S/A & 12.000 \\
\hline Subsistema A & 4.000 \\
\hline Subsistem a $Q_{3} / R_{3}$ & 12.000 \\
\hline Subsistema $\mathrm{R}_{4}$ & 6.000 \\
\hline Subsistema PPC & 9.000 \\
\hline \multicolumn{2}{|l|}{ SISTEMA CANASTRA } \\
\hline Subsistema F & 7.000 \\
\hline Subsistema $\mathrm{F} / \mathrm{Q} / \mathrm{M}$ & 33.000 \\
\hline SISTEMA BAMBUÍ & 5.000 \\
\hline SISTEMA ARAXÁ & 3.000 \\
\hline
\end{tabular}

com ampla continuidade lateral, compondo o sistema de águas subterrâneas rasas. Esses aquíferos geralmente são aproveitados por poços rasos, sendo a altura do nível freático (carga potenciométrica) controlada pela hipsometria e por feições físicas gerais dos vários tipos de solo/manto de intemperismo. Como são aqüíferos rasos e livres, são moderadamente susceptíveis à contaminação por agentes externos, sendo, em geral, isolados em sistemas de abastecimento público. Os volumes de água captados pelos poços rasos são sempre inferiores a $800 \mathrm{l} / \mathrm{h}$.

Em função dos parâmetros mencionados anteriormente (b e K), esse domínio pode ser dividido em quatro sistemas denominados $\mathrm{P}_{1}, \mathrm{P}_{2}, \mathrm{P}_{3}$ e $\mathrm{P}_{4}$. Os sistemas $\mathrm{P}_{1}, \mathrm{P}_{2}$ e $\mathrm{P}_{3}$ são caracterizados por grandes espessuras $(>5 \mathrm{~m})$ e condutividades hidráulicas respectivamente alta, média e baixa. $\mathrm{O}$ sistema $\mathrm{P}_{4}$ caracteriza-se por pequenas espessuras (comumente menores que 1 metro, podendo alcançar 2,5 m) e condutividade hidráulica baixa.

Esse domínio aqüífero apresenta particularidades devido ao fato de representar a transição entre a zona vadosa (incluindo a região onde ocorrem as interações entre o meio externo e os aqüíferos) e a zona saturada do aqüífero (águas mais profundas). Essa porção também inclui a região onde se originam os processos de recarga dos aqüíferos (rasos e profundos) a partir da infiltração pluviométrica. Uma importância adicional desse domínio está vinculada à manutenção da perenidade de drenagens no período de recessão de chuvas.

Os exutórios desse domínio estão relacionados a fontes do tipo depressão ou contato, sendo sua vazão média controlada pelo tipo de regime de fluxo. As fontes relacionadas a fluxos regionais e intermediários apresentam vazões superiores a 2,0 l/s, enquanto as de fluxo local mostram vazões reduzidas e com amplas variações sazonais. Os aqüíferos subjacentes, do domínio fraturado, também funcionam como importantes exutórios dos aquíferos do domínio poroso, pois são diretamente alimentados a partir da zona saturada contida nos solos e nas rochas alteradas.

Domínio Fraturado Os aqüíferos do domínio fraturado são caracterizados pelos meios rochosos, onde os espaços ocupados pela água são representados por descontinuidades planares, ou seja, planos de fraturas, microfraturas, diáclases, juntas, zonas de cisalhamento e falhas. Como no Distrito Federal o substrato rochoso é representado por metassedimentos, os espaços intergranulares foram preenchidos durante a litificação e o metamorfismo. Dessa forma, os eventuais reservatórios existentes nas rochas proterozóicas estão inclusos dentro do Domínio Fraturado, onde os espaços armazenadores de água são classificados como porosidade secundária.

Por estarem restritos a zonas que variam de alguns metros a centenas de metros, os aqüíferos do Domínio Fraturado são livres ou confinados, de extensão lateral variável, fortemente anisotrópicos e heterogêneos, compondo o sistema de águas subterrâneas profundas. Com raras exceções, esse domínio está limitado a profundidades pouco superiores a $250 \mathrm{~m}$, sendo que em profundidades maiores há uma tendência de selamento dos planos abertos pela pressão litostática.

Os parâmetros hidrodinâmicos são muito variáveis em função do tipo de rocha e, inclusive, variando significativamente em um mesmo tipo litológico. O principal fator que controla a condutividade hidráulica dos aquíferos desse domínio é a densidade das descontinuidades do corpo rochoso.

Esses aqüíferos são aproveitados por meio de poços tubulares profundos e apresentam vazões que variam de zero até valores 
superiores a $100.000 \mathrm{l} / \mathrm{h}$, sendo que a grande maioria dos poços apresenta entre 5.000 e $12.000 \mathrm{l} / \mathrm{h}$. A incidência de poços secos é controlada pela variação da fração psamítica, sendo que quanto maior a concentração de quartzitos menor a incidência de poços secos e quanto maior a presença de material pelítico (metassiltitos e ardósias) maior a ocorrência de poços secos ou de muito baixa vazão.

A base atualizada do conhecimento geológico, a análise estatística dos dados de vazões e as feições estruturais permitiram a classificação desse domínio em quatro conjuntos distintos, denominados de sistemas aquíferos Paranoá, Canastra, Araxá e Bambuí. O Sistema Paranoá foi subdividido nos seguintes subsistemas: S/ $\mathbf{A}, \mathbf{A}, \mathbf{R}_{3} / \mathbf{Q}_{3}, \mathbf{R}_{4}$ e PPC, enquanto o Sistema Canastra foi subdividido nos subsistemas: $\mathbf{F}$ e $\mathbf{Q} / \mathbf{F} / \mathbf{M}$.

As águas subterrâneas desse domínio apresentam exposição à contaminação atenuada, uma vez que os aqüíferos do Domínio Poroso sobrepostos funcionam como um filtro depurador natural, que age como um protetor da qualidade das águas mais profundas.

A recarga dos aquíferos desse domínio se dá através do fluxo vertical e lateral de águas de infiltração a partir da precipitação pluviométrica. A morfologia da paisagem é um importante fator controlador das principais áreas de recarga regionais.

PROPOSTAS PARA GESTÃO Os maiores problemas associados ao uso das águas subterrâneas no Distrito Federal estão relacionados à sobre-explotação localizada dos aqüíferos, à impermeabilização das áreas de recarga regionais, à má construção dos poços, à não observação dos parâmetros de proteção sanitária das obras de captação e à falta de conhecimentos específicos sobre as disponibilidades hídricas.

Para a adequada gestão do sistema é importante direcionar os esforços para as várias funções dos aquíf́eros, incluindo iniciativas que promovam a mitigação dos impactos que afetam as funções filtro, reguladora e armazenadora do aqüífero.

Função Filtro As obras de captação das águas profundas representam a maior intervenção na função filtro do aquíífero, uma vez que na região do Distrito Federal a ampla maioria das empresas de perfuração de poços não obedece as normas técnicas construtivas. A ausência de isolamento na zona vadosa do Sistema Poroso, pode acarretar em rápida contaminação das águas profundas, pois os efluentes podem infiltrar rapidamente através do pré-filtro, ou do espaço entre a parede do poço e o revestimento alcançando as fraturas mais profundas.

Outro fator negativo é a não observação do perímetro de proteção ao poço (PPP). Muitas vezes os poços tubulares são construídos junto a inúmeros focos potenciais de contaminação (principalmente fossas sépticas ou negras).

Para minimizar o risco de contaminação, dando ao sistema a oportunidade da lenta infiltração e filtragem dos efluentes ao longo da zona vadosa, é importante observar as normas construtivas, tomando especial atenção para o isolamento sanitário dos primeiros 10 ou $15 \mathrm{~m}$ do poço. E importante também obedecer a distância mínima de $30 \mathrm{~m}$ de qualquer fonte potencial de contaminação.

Uma iniciativa importante na questão da gestão das águas subterrâneas é a realização de estudos sobre a vulnerabilidade natural ou riscos potenciais de contaminação dos aquiíferos, os quais podem direcionar os tipos de uso e ocupação do solo, além de auxiliar no planejamento da expansão dos núcleos urbanos e regi- ões industriais.

Para o Distrito Federal foi confeccionado um mapa de vulnerabilidade a partir da integração digital (utilização de sistemas de informações geográficas) de dados geológicos, hidrogeológicos, geomorfológicos, pedológicos, de cobertura vegetal e de pontos potenciais de contaminação (Fig. 2).

Função Reguladora Esta função está relacionada ao papel dos aqüíferos como alimentadores da rede de drenagem superficial, isto é, transmissão lenta das águas de chuva para a manutenção da perenidade da rede hidrográfica nos meses com pouca ou nenhuma precipitação pluviométrica. A elevada taxa de bombeamento em certas áreas e a intensa impermeabilização acarreta no rebaixamento demasiado dos níveis dinâmicos, comprometendo as vazões dos cursos superficiais. Esse processo, em longo prazo, pode inclusive levar ao secamento total de nascentes, drenagens e lagoas.

Para minimizar esse efeito negativo, propõe-se um manejo integrado com sistemas de abastecimento misto, utilizando recursos hídricos superficiais e subterrâneos. Assim, nos locais onde existe a possibilidade de viabilizar captações em pequenas drenagens, a água superficial poderia ser utilizada durante os meses chuvosos, quando as vazões normalmente aumentam até 4 vezes com relação à vazão de base. No período seco esses pontos de captação poderiam ser limitados a pequenos volumes, uma vez que as vazões ficam bastante reduzidas, garantindo aos cursos superficiais as funções de manutenção dos ecossistemas, diluição de efluentes e abastecimento dos aqüíferos.

A contribuição da água subterrânea apresentaria um comportamento inverso, isto é, teria máxima vazão durante os meses secos e mínimo bombeamento nos períodos chuvosos. Assim, durante os meses com superávit hídrico os níveis dos sistemas aquíferos são recuperados de forma que os volumes adicionais sejam disponibilizados para os períodos mais secos. Esse processo resulta em um balanço onde a reserva adicionada nos períodos de maior precipitação poderá ser utilizada para o abastecimento durante os meses secos.

Esse tipo de sistema de abastecimento pode ser facilmente operado desde que se estimem os valores médios de vazões e se construa um sistema integrado entre os reservatórios e as redes de distribuição. Ainda há uma vantagem adicional no sentido de absorver com maior facilidade os impactos de variações climáticas sazonais (e.x. secas prolongadas ou inversões esporádicas de meses mais ou menos chuvosos).

Função Armazenadora Está relacionada à característica econômica dos aqüíferos, sendo diretamente vinculada aos volumes de água reservados nos meios geológicos. Esta função é afetada principalmente pela impermeabilização das áreas de recarga regionais e pela sobrexplotação dos aqüíferos.

No Distrito Federal são definidas como áreas de recarga regionais as regiões com relevo plano e elevado (região de Chapadas Elevadas) recobertas por solos de textura média a arenosa com elevada capacidade de infiltração. Nestas áreas um volume superior a $20 \%$ da precipitação total infiltra através da zona vadosa do domínio poroso para recarregar a zona saturada do domínio aqüífero fraturado (Zoby 1999e Carmelo 2002).

Com a ocupação e conseqüente impermeabilização da superfície o volume infiltrado diminui significativamente, resultando em um aumento do fluxo superficial total pela interceptação artificial. Como a recarga natural dos aquíferos se dá a partir da infiltração 

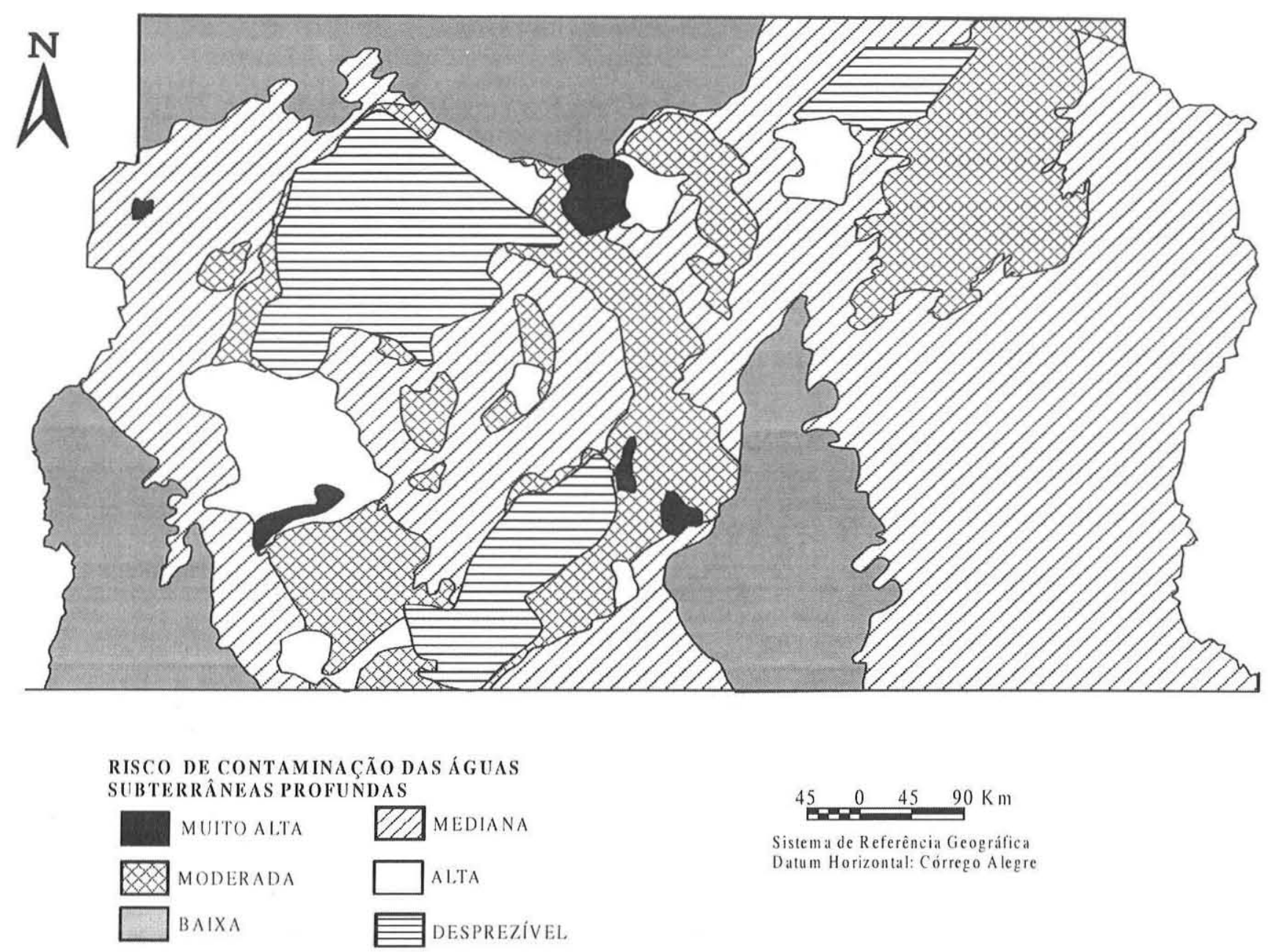

Figura 2 - Mapa de risco de contaminação das águas subterrâneas profundas do Distrito Federal (segundo Campos \& FreitasSilva 1998).

da água de precipitação pluviométrica, através da zona vadosa do aquiífero, até alcançar sua zona de transição e ocupar a porção saturada do domínio rochoso, a expansão urbana causa a impermeabilização de grandes áreas (ruas, passeios, coberturas de residências, etc) o que causa uma drástica redução da infiltração natural e aumento do fluxo superficial total ( run off), resultando na diminuição da recarga natural dos aquíf́ros. Esse fato já pode ser observado em condomínios da região da cidade de Sobradinho-DF. Como exemplo, pode-se citar o caso do Condomínio Alto Bela Vista onde um poço com vazão de $10.0001 / \mathrm{h} \mathrm{em} \mathrm{1992,}$ passou a uma vazão de cerca de $3.500 \mathrm{l} / \mathrm{h}$ no ano 2000 .

Para minimizar esse impacto sobre o sistema natural, é recomendável o desenvolvimento da prática de recarga artificial dos aqüíferos. A recarga artificial consiste de qualquer processo que induza infiltração ou injeção de água nos aqüíferos, podendo ser realizada através de caixas ou barragens de infiltração, espalhamento de água sobre o solo, sulcos paralelos às curvas de nível, poços de injeção, etc (Fetter 1994).

As práticas de recarga artificial são bastante utilizadas em várias regiões do mundo com objetivos variados como mostram os seguintes exemplos: Fresno, Califórnia (Salo et al. 1986), visando minimizar contaminação de aqüíferos; Las Vegas Valley, Nevada (Katzer \& Brothers 1989), objetivando aumentar a água disponível para abastecimento público; Filadélfia, Paraguai (Godoy et al. 1994), com o intuito de aumentar o volume de água para irrigação; Orange County, Califórnia (Matthews, 1991), para recarregar aqüíferos com água de rio; Alemanha, para a regularização da temperatura e $\mathrm{pH}$, a partir de águas tratadas com origem variada; Karany, República Checa (Knezek \& Kubala 1994), para viabilizar o abastecimento público da Cidade de Praga; e Norte de Londres, Inglaterra (O'Shea 1994), para gestão de áreas semi-áridas.

Para o caso específico do Distrito Federal, é proposta a metodologia de caixas de recarga, preenchidas com material permeável (materiais com elevada condutividade hidráulica) para induzir a infiltração. Outra alternativa é o uso de caixas com revestimento permeável (similar a sumidouros de sistemas de esgotamento individual). As caixas deverão ser alimentadas por água de chuva captada em coberturas de residências nos meses de maior índice pluviométrico, no sentido de aproveitar o excedente hídrico das precipitações, principalmente entre os meses de novembro e março. As caixas serão construídas preferencialmente nas áreas verdes dos lotes (geralmente áreas com coberturas de grama) o mais afastado possível das edificações para evitar problemas geotécnicos.

A proposta aqui apresentada vem sendo aplicada em sistemas pilotos e os resultados preliminares da pesquisa são apresenta- 
dos por Cadamuro (2002). Os melhores resultados são obtidos com o uso de caixas com formado cilíndrico com dimensões da ordem de 2,5 m de profundidade por $1 \mathrm{~m}$ de diâmetro preenchidas por cascalho lavado (granulometria de 0,5 a 2,0 mm).

Deve ser utilizada água de precipitação pluviométrica (com pequena permanência na superfície), para minimizar o potencial de contaminação e infiltração de particulados que impermeabilizam as porções rasas dos aquíiferos. A melhor opção é a utilização de águas coletadas nas calhas da cobertura de residências (telhado), por se tratar de uma água limpa, a qual não trará qualquer risco à contaminação dos mananciais subterrâneos. A água coletada das calhas será dirigida para as caixas permeáveis e no caso de saturação, o excesso de água será canalizado para o sistema de drenagem de águas pluviais.

A metodologia ora proposta espera contribuir para a resolução de problemas ligados à gestão dos recursos hídricos subterrâneos, de forma a elevar o potencial do uso das águas subterrâneas através da explotação dos aquíferos fraturados, compensando a diminuição causada pela interceptação artificial. Finalmente espera-se alcançar a sustentabilidade do sistema aquífero nas situações onde as áreas de recarga apresentam sobreposição com as áreas ocupadas.

CONCLUSÕES A disponibilidade hídrica subterrânea no Distrito Federal é limitada. Esse recurso deve ser utilizado de forma estratégica para objetivos específicos. O mau uso e a ocupação inadequada do solo determinam a necessidade de desenvolvimento de práticas de gestão dos sistemas aquiíferos.

A proteção sanitária dos poços tubulares é a única forma de garantir a função filtro da zona vadosa dos aquíferos. O isolamento da porção rasa entre o revestimento e a parede do poço e a manutenção de distâncias mínimas entre pontos potenciais de contaminação e os pontos de captação são medidas importantes para a proteção do aqüífero. O controle da qualidade técnica das empresas construtoras de poços é uma medida eficaz na questão da gestão da qualidade das águas subterrâneas.

A viabilização de sistemas de abastecimento misto com uso de mananciais subterrâneos e superficiais é uma prática que pode garantir a função reguladora dos aquiíferos. Nesse sentido, a máxima derivação dos recursos hídricos subterrâneos deve ser feita durante os meses mais secos do ano, enquanto que no período chuvoso, em função do superávit hídrico superficial, sua contribuição para o abastecimento deverá ser maior.

A implantação de sistemas de recarga artificial é fundamental para a estabilização do rebaixamento regional do nível estático, uma vez que a infiltração natural vem sendo limitada progressivamente com a urbanização, diminuindo a vazão de segurança. Esse processo é a única alternativa para a gestão racional do uso das águas subterrâneas na região, garantindo a auto-sustentabilidade do sistema aqüífero fissural do Distrito Federal.

O tempo de bombeamento diário de 14 horas é compatível com o sistema aquífero fissural do Distrito Federal, sendo que as 10 horas diárias restantes são importantes para a recuperação dos níveis e para a limitação dos cones de depressão na região.

A recarga artificial, por caixas permeáveis, é ideal para o tipo de ocupação urbana que vem sendo desenvolvido no DF, sendo compatível com as características físicas da zona vadosa do aquíffero. A água para recarga deverá ser captada a partir de coberturas de residências nos períodos com excedente hídrico. Trata-se de uma água com pequena permanência superficial não acarretando em qualquer risco de contaminação dos aquííferos.

Com o incremento da ocupação de áreas urbanas e aumento de operação de poços tubulares, os níveis estáticos deverão ser monitorados continuamente, sendo fundamental a instalação de hidrômetros e tubos piezométricos nas fases de construção dos poços.

Por fim, ressalta-se a necessidade de monitoramento da exploração d'água subterrânea visando à racionalização de seu uso. Esse monitoramento é também importante para somar informações sobre a eficiência dos sistemas de gestão propostos, bem como de outros que por ventura possam ser implantados, de forma a agregar dados sobre o sistema hidrogeológico local e regional.

Agradecimentos Aos revisores da RBG pelas sugestões ao manuscrito.

\section{Referências}

Amore L. 1994. Fundamentos para uso e proteção das águas subterrâneas do Distrito Federal. Escola de Engenharia de São Carlos (Dissertação de Mestrado - inédita).

Barros J.C.B. 1987. Geologia e hidrogeologia do Distrito Federal. In: GDF/CAESB Inventário hidrogeológico do Distrito Federal. Brasília DF. P. $79-330$.

Barros J.G.C. 1994. Características geológicas e hidrogeológicas do Distrito Federal. In: UnB/SEMATEC Cerrado, caracterização, ocupaçãoe perspectivas - O caso do Distrito Federal., 657p.

Baptista G.M.M. 1998. Caracterização climatológica do Distrito Federal. In: IEMA/SEMATEC/UnB, Inventário Hidrogeológico e dos Recursos Hídricos Superficiais do Distrito Federal. Brasília.. Vol. 1, 187-208p.

Cadamuro A.L.M. 2002. Proposta, avaliação e aplicabilidade de técnicas de recarga artificial em aqǘferos fraturados para condomínios residenciais do Distrito Federal. Brasília. 126p. (Dissertação de
Mestrado, Instituto de Geociências, Universidade de Brasília).

Carmelo A.C. 2002. Caracterização de aquiíferos fraturados por integração de informações geológicas e geofísicas. Brasília. 161p. (Tese de Doutorado, Instituto de Geociências, Universidade de Brasília).

Campos J.E.G. \& Freitas-Silva F.H. 1998. Hidrogeologia do Distrito Federal. In: Inventário hidrogeológico e dos recursos hídricos superficiais do Distrito Federal. Parte I. Vol II. IEMA-SEMATEC/ Universidade de Brasília. (Inédito). 66p.

Campos J.E.G. \& Freitas-Silva, F.H. 1999. Arcabouço hidrogeológico do Distrito Federal. In: SBG, Simp. Geol. Centro-Oeste, 12, Boletim de Resumos. Brasília. 113p.

CODEPLAN 1984. Atlas do Distrito Federal. Brasília. Secretaria de Educação e Cultura/CODEPLAN. v. 1. 78p.

Coimbra A.R.S.R. 1987. Balanço hídrico preliminar do Distrito Federal. 
In: IEMA/SEMATEC/UnB 1998, Inventário hidrogeológico do Distrito Federal. (GDF/CAESB) Brasília DF. P. 50-78.

Faria A. 1995. Estratigrafia e sistemas deposicionais do Grupo Paranoá nas áreas de Cristalina, Distrito Federal e São João D'Aliança-Alto Paraíso de Goiás. Brasília. 199p. (Tese de Doutorado, Instituto de Geociências, Universidade de Brasília).

Fetter C.W. 1994. Applied hydrogeology. McMillan College Publ. Co. New York. 680p.

Freitas-Silva F. H. \& Dardenne, M. A. 1994. Proposta de subdivisão estratigráfica formal para o Grupo Canastra no oeste de Minas Gerais e leste de Goiás. In: SBG, Simp. Geol. Centro-Oeste, 4. Brasília, 1991. Anais...Brasília, SBG-DF/CO, p.164-165.

Freitas-Silva F.H. \& Campos J.E.G. 1998. Geologia do Distrito Federal. In: IEMA/SEMATEC/UnB 1998. Inventário Hidrogeológico e dos Recursos Hidricos Superficiais do Distrito Federal. Brasília. IEMA/ SEMATEC/UnB. Vol. 1, Parte I. 86p. (Relatório Inédito).

Godoy E.V., Garcia D.S., Farina S.L. 1994. Recarga artificial de acuifero freatico en Filadelfia - Chaco Central Paraguaio. In: Congr. Brasil. de Águas Subterrâneas, 13, Anais, pp.: 385-393. Recife/PE.

Joko C.T. 2002. Hidrogeologia da região de São Sebastião - DF: implicações para a gestão do sistema de abastecimento de água. Brasília. 158p. (Dissertação de Mestrado, Instituto de Geociências, Universidade de Brasília).

Katzer, T. \& Brothers, K. 1989. Artificial recharge in Las Vegas Valley, Clark County, Nevada. Ground Water 27(1):50-56

Knezek M. \& Kubala P. 1994 Experience with artificial groundwater recharge in Karany. In: Reeve \& Watts (eds.) Groundwater Drought, pollution \& management. Balkema, Rotterdam. 235- 242.

Maio C.R. 1986. Alterações ambientais no Distrito Federal, baseadas na geomorfologia dinâmica. Rev. Bras. Geogr., 48(3):259-284.

Marini O.J., Fuck R.A., Danni J.C. 1981. A evolução geotectônica da Faixa Brasília e do seu embasamento. In: SBG, Simp. sobre o Cráton do São Francisco e Suas Faixas Marginais, 1. Salvador, 1981. Anais..., Salvador, SBG/BA. p. 100-113.

Martins E.S. \& Baptista G.M.M. 1998. Compartimentação geomorfológica e sistemas morfodinâmicos do Distrito Federal. In: IEMA/SEMATEC/UnB 1998. Inventário Hidrogeológico e dos Recursos Hídricos Superficiais do Distrito Federal. Brasília. IEMA/ SEMATEC/UnB. Vol. 1, Parte II. 53p.

Matthews C. 1991. Using ground water basins as storage facilities in Southern California. Water Resouces Bulletin, 17:841-847.
Mendonça A. F. 1993. Caracterização da erosão subterrânea nos aqüíferos porosos do Distrito Federal. Anexo 3a: Reservas de água de superfície do Parque Nacional de Brasília. Brasília. Universidade de Brasília/Instituto de Geociências. 154p. (Dissertação de Mestrado - inédita)

Novaes Pinto M. \& Carneiro P.J.R. 1984. Análise preliminar das feições geomorfológicas do Distrito Federal. In: Congr. Bras. de Geógrafos. 4. 1984. Anais, São Paulo. Livro II, v.2. p.190-213.

Novaes Pinto M. 1986a. Caracterização morfológica do Curso Superior do Rio São Bartolomeu - Distrito Federal. Rev. Bras. Geogr., 48(4):377-397.

Novaes Pinto M. 1986b. Unidades geomorfológicas do Distrito Federal. Geografia, 11(21):97-109.

Novaes Pinto M. 1987. Superfícies de aplainamento do Distrito Federal. Rev. Bras. Geogr., 49(2):9-26.

Novaes Pinto M. 1994a. Caracterização geomorfológica do Distrito Federal. In: M. Novaes Pinto (org.) Cerrado: caracterização, ocupação e perspectivas. Brasília. Editora UnB. 2“ ed. p. 285-320.

Novaes Pinto, M. 1994b. Paisagens do cerrado no Distrito Federal. In: M. Novaes Pinto (org). Cerrado: caracterização, ocupação e perspectivas. Brasília. Editora UnB. 2" ed. p. 511-542.

O'shea M.J.O. 1994. Drought management using artificial aquifer in north London. In: Reeve \& Watts (eds). Groundwater - Drought, pollution \& management, Balkema, Rotterdam. p.223-233.

Romano O. \& Rosas, J. G. C. 1970. Água subterrânea para fins de abastecimento de água e irrigação no Distrito Federal. In: SBG, Congr. Bras. Geol., 24. 1970. Anais..., Brasília, SBG. p.313-333.

Salo J.E.D., Harrison D., Archibald E.M. 1986. Removing contaminants by ground water recharge basins. J. Am. Water Works Association, 78(79):76-81.

Souza M.T. 2001. Fundamentos para a gestão dos recursos hídricos subterrâneos no Distrito Federal. Brasília. Universidade de Brasília/ Instituto de Geociências. 124p. (Dissertação de Mestrado, inédita).

Zoby J.L.G. 1999. Hidrogeologia de Brasília - Bacia do Ribeirão Sobradinho. São Paulo. Universidade de São Paulo - Instituto de Geociências. (Dissertação de Mestrado - inédita). 178p.

Manuscrito A-1372

Recebido em 24 de setembro de 2002

Revisão do autor em 15 de novembro de 2003 Revisão aceita em 30 de novembro de 2003 